\title{
A study of the efficacy of fathers' attachment training on paternal-fetal attachment and parental anxiety
}

\author{
SARA SETODEH ${ }^{1, B, F}$, SAEEDEH POURAHMAD², c, MARZIEH AKBARZADEH ${ }^{3, \text { A, D-G }}$ \\ ${ }^{1}$ Department of Midwifery, Student Research Center, School of Nursing and Midwifery, Shiraz University \\ of Medical Sciences, Shiraz, Iran \\ ${ }^{2}$ Department of Biostatistics, School of Medicine, Shiraz University of Medical Sciences, Shiraz, Iran \\ ${ }^{3}$ Maternal-Fetal Medicine Research Center, Department of Midwifery, School of Nursing and Midwifery, \\ Shiraz University of Medical Sciences, Shiraz, Iran
}

A - Study Design, B - Data Collection, C - Statistical Analysis, D - Data Interpretation, E - Manuscript Preparation, F - Literature Search, G - Funds Collection

Summary Background. Attachment behaviors play an important role in accepting the identity of the fathers, the pleasant outcome of pregnancy and the child's growth and development in the future.

Objectives. This study aimed to investigate the effect of father's attachment training (awaiting a child) on paternal-fetal attachment and parental anxiety.

Material and methods. This clinical trial was conducted on 150 spouses of eligible pregnant women. In the intervention group, four 90-minute training sessions were designed on maternal-fetal attachment, while the control group received routine prenatal care. The questionnaire of paternal-fetal attachment was completed both before and after intervention in both cases and control groups. Data analysis was done in SPSS software using a paired $t$-test and independent $t$-test (the significant level was 0.05 ).

Results. The mean score of attachment was reported as $56.61 \pm 6.05$ and $64.53 \pm 6.94$ both before and after intervention, respectively. According to the paired $t$-test, there was a significant difference in the attachment score after intervention $(p<0.001)$. According to the independent $t$-test applied a month after intervention, the comparison of fathers' anxiety scores before and after intervention showed a significant difference between the control and intervention groups $(p<0.001)$.

Conclusions. Training fathers about attachment skills leads to increased paternal-fetal attachment and a lower anxiety score. Therefore, it seems necessary to include education of fathers in prenatal care.

Key words: education, attachment, father, infant.

Setodeh S, Pourahmad S, Akbarzadeh M. A study of the efficacy of fathers' attachment training on paternal-fetal attachment and parental anxiety. Fam Med Prim Care Rev 2017; 19(4): 393-398, doi: https://doi.org/10.5114/fmpcr.2017.70814.

\section{Background}

Maternal-fetal attachment (MFA) is one of the best strategies to address maternal stress during pregnancy. The factors affecting MFA include family relationships, pregnancy acceptance, support of others, the mothers' self-image, history of previous pregnancies, pregnancy complications, unwanted pregnancy, age and level of education [1]. MFA is the most typical and sophisticated type of communication that can make an effective impression on health care, raising a child at the start of life, good practice and a good foundation for his/her future communication [2]. Over the past 20 years, many studies have been carried out on the correlation of MFA and the bond between the mother and infant after birth. Despite previous studies, we did not find enough studies on MFA in comparison to studies on post-partum attachment [3].

Fleming et al. and Muller proved the correlation between MFA and the bond between a mother and child after birth in their studies [4, 5]. Zachariah also confirmed the link between physiologic health, distress and MFA in his study [6]. The presence of a child is considered an impressive developmental phenomenon for fathers who experience it for the first time, and his emotional change is considered less in comparison to the mother's mental changes.

Pregnancy causes some definitive physiological changes in the sexual partner, too. Furthermore, labor and delivery are considered as difficult experiences for fathers. Fathers losing their paternal role will be exposed to losing their mental health. The issue of becoming a father is considered the most important phase of their developing process. Research has reported various reactions in men facing the labor and delivery phase:

1. Some declare the same feeling as their spouse experiencing labor and delivery [7].

2. Some express their sadness about their role as "supporter" in the labor phase, most typically in younger fathers who experience it [8].

3. Some believe they were ignored or a burden in their secondary role in the pregnancy process [9].

4. Fathers who were training, prepared and waited during pregnancy, found that the reality of the baby's birth was different from their perception [10].

Johnson conducted a study on 53 British men whose wives had normal vaginal delivery. The study was done 60 hours after delivery and showed that $57 \%$ of men felt under enormous pressure at the time of birth. About $56 \%$ of men were concerned about the pain their spouse had, and $38 \%$ believed they were not effective in supporting their spouse. About $56 \%$ stated a feeling of hindering the path of their partner, and $22 \%$ did not attend the birth of the child [11]. According to Henderson and Brouse, in the USA and Britain, fathers declared a feeling of anxiety, discomfort and sever distressed during the first weeks after birth to their baby [12]. Despite the positive expectations about 
the father's satisfaction after birth, some studies have shown a relative experience of discomfort within the first months [13].

Ballard studied the post-partum depression in fathers whose wives had a recent delivery in hospitals in England. The study tools were emailed to all subjects and assessed by psychological tables. The rate of depression was estimated as $9 \%$ and $54 \%$ in the first 6 weeks and 6 months after birth, respectively [14]. Studying the role of fathers in supporting maternal health has been a slow process, so it seems necessary to investigate the role of fathers in promoting family health [15]. Jordan believes that fathers will perform their paternal role more effectively if they are more involved in their partner's experiences besides just interaction with the child. Based on these findings, the participation of men in the process of pregnancy is very effective in the health of their wives, infants and the whole family [9]. Latifses did a study in 2005 on fathers waiting for the birth of their child. It showed that those who were taught to massage their spouse had a higher score of adaptation and paternal attachment with less anxiety compared to the control group [15]. According to the study done by Weinfeld et al. in 1999, a father's perception about the couple's adaptation is in agreement with his attachment to the fetus, which consequently leads to less anxiety [16]. According to the above studies, involving the spouses of pregnant women in the health and treatment process of pregnancy, labor and delivery is essential in promoting his paternal role, emotion and interactions. This point has been the focus of research on maternal-fetal attachment, which was considered in the present study as well. Educating and engaging fathers in the pregnancy process of their wives can significantly impact the mental health in women and infants and eventually lead to better and more effective interaction. It can reduce the rate of anxiety in both men and women. Midwives are an important element of health and play an important role in family health by changing the fathers' attitude. Therefore, this study aimed to investigate the effect of a father's attachment training (awaiting a child) on paternal-fetal attachment and his anxiety.

\section{Material and methods}

This is an experimental study aiming to investigate the effect of fathers' training (waiting for their child to be born) on paternal-fetal attachment. The research subjects were the spouses of all nulliparous pregnant women referring to the prenatal clinics of the Hafez and Shoshtari hospitals. A sample size of 120 was calculated regarding the relevant articles $[15,17]$ by applying the following formula and considering $\alpha=0.05,1-\beta=0.80$, mean difference $=1$, and $\sigma=3$, was determined for the study:

$$
N=\frac{2\left(Z_{1-\partial / 2}+Z_{1-\beta}\right)^{2} \sigma^{2}}{\left(\mu_{2}-\mu_{1}\right)^{2}} .
$$

However, considering the probability of loss, 150 couples (75 couples in each group) was determined (Figure 1). At first, 150 mothers who met the inclusion criteria of the study were selected through purposive sampling and selection, and block randomization was used to divide participants into the interventional and control groups. Written informed consent was then obtained from the participants, and they were explained the study procedure.

The inclusion criteria included nulliparous women, aged between 18 to 35 years, live singleton pregnancy with a gestational age of 28-34 weeks, no history of maternal mental and maternal chronic diseases, receiving pregnancy care in prior months and having low or average anxiety levels according to Spiel Berger anxiety scale. In addition, the fathers' inclusion criteria were to have at least a middle school degree who could participate in the training classes with signed written informed consent. Exclusion criteria were lack of willingness to cooperate, any complications of pregnancy during the study (placental abruption, umbilical cord prolapse and abnormal fetus position, placenta Previa, etc.). Data collection was done through a personal form (including demographic information of the mother and father and information on the pregnancy of mothers and her mental health, a fathers' attachment questionnaire and via the Spiel Berger anxiety scale. The paternal-fetal questionnaire was made based on the Cranly questionnaire, designed to assess MFA in 5 subscales, including interaction with the fetus (5 items), differentiation of fetus and self ( 4 items), acceptance of paternal role (4-items), assigning certain properties to the fetus ( 6 items) and devotion (5 items). The scoring range was 24 to 72, based on the 3-point Likert scale. The questionnaire's reliability was determined by a test-retest method (on 30 subject and a re-test in 10 days later) and reporting Cronbach's alpha as 0.75 among the peers and experts to ensure face and content validity.

The Spiel Berger Scale was used to measure anxiety (contains 40 questions with a score of 80). The State-Trait Anxiety Inventory (STAI) is a commonly used measure of trait and state anxiety. Both the A-State and A-Trait scales comprise 20 items each and are scored on 4-point forced-choice Likert-type response scales. The scores range from 20 to 80 , with higher scores suggesting greater levels of anxiety. Low scores (20-40) suggest mild anxiety, median scores (41-60) suggest moderate anxiety, and high scores (61-80) mean severe anxiety [18]. Aghamohammadi used Spiel Berger's scale to determine the validity and reliability of the questionnaire, which proved to be $97 \%$ [19].

The sampling was purposefully based on having a low to moderate level of anxiety (based on the Spiel Berger scale), along with having the inclusion criteria for her spouse. Attachment behavior education was provided for the group of qualified spouses, and a group was selected as the control group. The study was not blinded in the education stage, but the researchers who evaluated paternal-fetal attachment and parental anxiety and analyzed the data and compared them to the control group were blinded to the assignment.

The fathers were trained regarding attachment skills through four 60 to 90 -minute sessions held once a week. The questionnaires were completed at the start of the study and immediately after intervention (lasting for one month).

\section{Statistical analysis}

The collected data was encoded and analyzed in SPSS (version 16, SPSS Inc., Chicago, IL, USA). The main tests for the assessment of normality of data are Kolmogorov-Smirnov (K-S) test. Regarding the data normalization, paired $t$-test was used for analysis. The mean scores before and after intervention in each group was compared using a paired $t$-test. Along with this, an independent $t$-test was used in order to compare father-fetal attachment scores in the interventional and control groups.

A: Tests of Normality for paternal-fetal attachment, anxiety

\begin{tabular}{|c|c|c|c|c|c|}
\hline \multirow{3}{*}{\begin{tabular}{|l} 
Variable \\
Father \\
attach- \\
ment
\end{tabular}} & \multirow[t]{2}{*}{ Time } & \multirow[t]{2}{*}{ Group } & \multicolumn{3}{|c|}{ Kolmogorov-Smirnov } \\
\hline & & & Sig. & $\begin{array}{l}\text { Num- } \\
\text { ber }\end{array}$ & $\begin{array}{l}\text { Statis- } \\
\text { tic }\end{array}$ \\
\hline & $\begin{array}{l}\text { before inter- } \\
\text { vention }\end{array}$ & attachment & 0.103 & 75 & 0.049 \\
\hline & & control & 0.092 & 75 & 0.191 \\
\hline & $\begin{array}{l}\text { after inter- } \\
\text { vention }\end{array}$ & attachment & 0.091 & 75 & 0.199 \\
\hline & & control & 0.086 & 75 & $0.200 *$ \\
\hline \multirow[t]{4}{*}{$\begin{array}{l}\text { Total } \\
\text { anxiety }\end{array}$} & $\begin{array}{l}\text { before in- } \\
\text { tervention }\end{array}$ & attachment & 0.089 & 75 & $0.200 *$ \\
\hline & & control & 0.094 & 75 & 0.095 \\
\hline & $\begin{array}{l}\text { after inter- } \\
\text { vention }\end{array}$ & attachment & 0.049 & 75 & $0.200^{*}$ \\
\hline & $\begin{array}{l}\text { before in- } \\
\text { tervention }\end{array}$ & control & 0.095 & 75 & 0.092 \\
\hline
\end{tabular}

aLilliefors Significance Correction; *This is a lower limit of the true significance. 


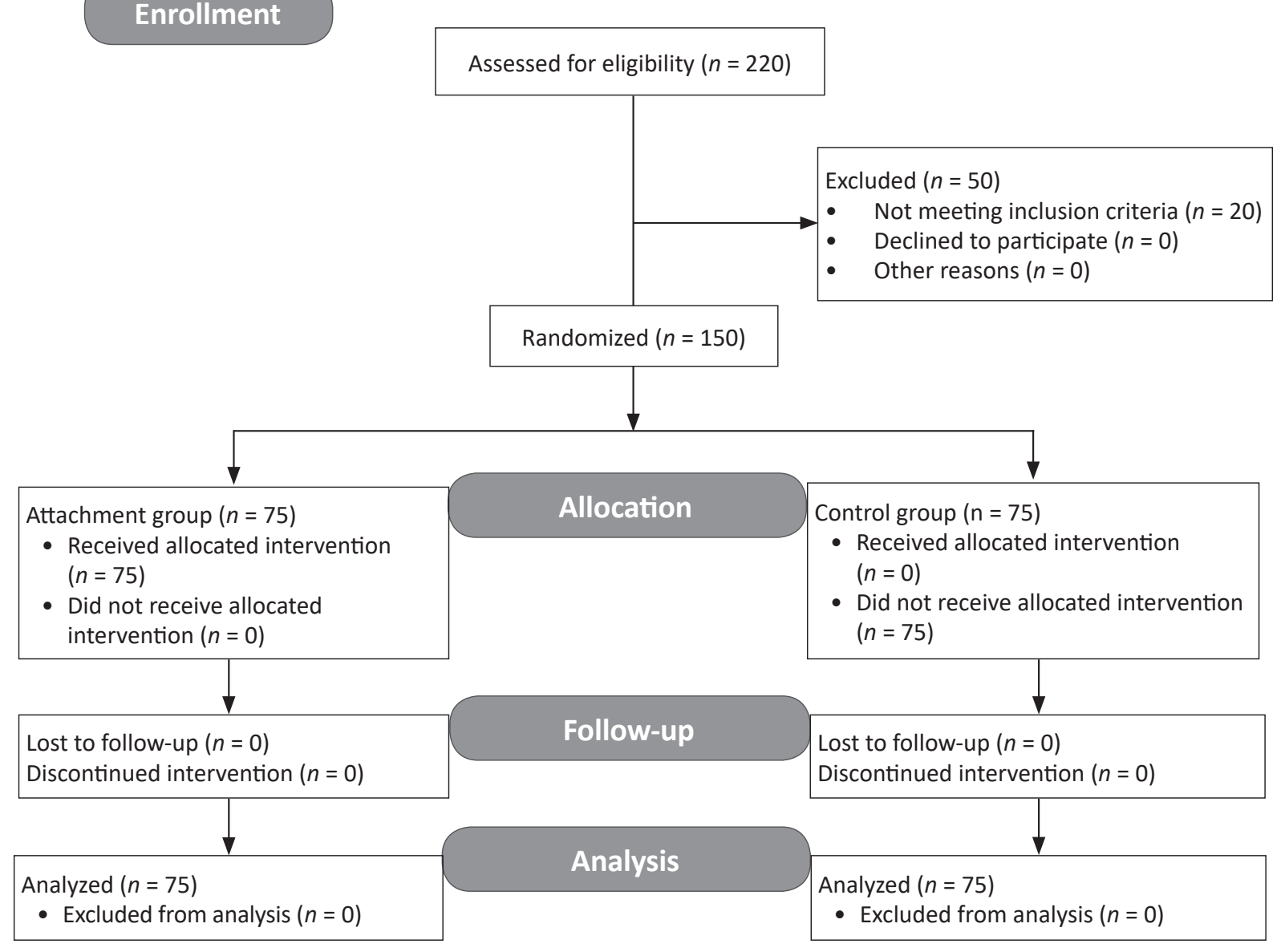

Figure 1. Study protocol consort diagram

\section{Results}

Both groups were matched in terms of age $(p=0.421)$, spouses' job $(p=0.237)$, and education $(p=0.126)$. The mean age of the study husbands was 29.03 years.

The most and least frequent age group was $26-30$ years $(44.7 \%)$ and $36-40$ years $(5.3 \%)$, respectively (Table 1$)$. The highest and lowest education level belonged to middle school (40\%) and high school (6\%), respectively (Table 2). According to Table 5, based on the independent $t$-test, no significant correlation was found in fetal paternal attachment before and after intervention ( $p=0.52)$; however, it was significant a month after the intervention $(p=0.001)$ due to the effect of intervention. In the intervention group, the mean score of attachment was $56.61 \pm 6.05$ and $64.53 \pm 6.94$ before and after intervention, respectively. The paired $t$-test showed a significant difference in attachment scores $(p<0.001)$. In the control group, the mean score of attachment was $57.34 \pm 7.85$ and $58.21 \pm 8.04$ before and after intervention, respectively. The difference was significant a month after intervention. In fact, the routine education provided in hospitals causes a change in attachment scores as compared to the beginning of the study (Table 3). According to independent $t$-test results, both groups were matched regarding the anxiety score $(p=0.63)$. However, a month after intervention, there was a significant change in the fathers' anxiety scores $(p<0.001)$

In the intervention group, the score of anxiety was reported as $45.78 \pm 5.28$ and $44.44 \pm 5.86$ a month after the education of MFA skills. According to the paired $t$-test, the decrease of anxiety was significant after intervention $(p=0.008)$. In the control group, the score of anxiety was reported as $45.39 \pm 4.93$ and $48.44 \pm 3.93$ a month later, respectively. According to the paired $t$-test, the increase in anxiety was significant after intervention $(p<0.001)$ (Table 4).

\begin{tabular}{|c|c|c|c|c|c|c|}
\hline \multirow[b]{2}{*}{ Frequency } & \multicolumn{2}{|c|}{ Attachment } & \multicolumn{2}{|c|}{ Control } & \multicolumn{2}{|c|}{ Total } \\
\hline & $n$ & $\%$ & $n$ & $\%$ & $n$ & $\%$ \\
\hline $20-25$ & 18 & 24 & 11 & 14.7 & 29 & 19.3 \\
\hline $26-30$ & 32 & 42.7 & 35 & 46.6 & 67 & 44.7 \\
\hline $31-35$ & 21 & 28 & 24 & 32 & 45 & 30 \\
\hline $36-40$ & 3 & 4 & 5 & 6.7 & 8 & 5.3 \\
\hline $41-45$ & 1 & 1.3 & 0 & 0 & 1 & 0.7 \\
\hline Total & 75 & 100 & 75 & 100 & 150 & 100 \\
\hline
\end{tabular}




\begin{tabular}{|c|c|c|c|c|c|c|}
\hline \multirow[t]{2}{*}{ Department of Education } & \multicolumn{2}{|c|}{ Experiment } & \multicolumn{2}{|c|}{ Control } & \multicolumn{2}{|c|}{ Total } \\
\hline & $n$ & $\%$ & $n$ & $\%$ & $n$ & $\%$ \\
\hline Guidance & 32 & 42.7 & 28 & 37.3 & 60 & 40 \\
\hline High school & 7 & 9.3 & 2 & 2.7 & 9 & 6 \\
\hline Diploma & 28 & 37.3 & 29 & 38.7 & 57 & 38 \\
\hline Collegiate & 8 & 10.7 & 16 & 21.3 & 24 & 16 \\
\hline Total & 75 & 100 & 75 & 100 & 150 & 100 \\
\hline
\end{tabular}

\begin{tabular}{|c|c|c|c|}
\hline Husband & $\begin{array}{l}\text { Attachment } \\
\text { group mean (SD) }\end{array}$ & $\begin{array}{l}\text { Control group } \\
\text { mean (SD) }\end{array}$ & $P$ \\
\hline Attachment before intervention & $56.61 \pm 6,05$ & $57.34 \pm 7.85$ & .523 \\
\hline Attachment after intervention & $64.53 \pm 6.94$ & $58.21 \pm 8.04$ & $<0.001$ \\
\hline $\begin{array}{l}\text { Paired } t \text {-test (within group) before and after } \\
\text { independent sample test (between group) } \\
\text { between the intervention and control }\end{array}$ & $<0.001$ & $<0.001$ & \\
\hline
\end{tabular}

\begin{tabular}{|c|c|c|c|c|c|}
\hline \multirow{2}{*}{$\begin{array}{l}\text { Husbands } \\
\text { Anxiety before intervention }\end{array}$} & \multicolumn{2}{|c|}{$\begin{array}{l}\text { Group attachment } \\
\text { mean (SD) }\end{array}$} & \multicolumn{2}{|c|}{\begin{tabular}{|l|} 
Control group \\
mean (SD) \\
\end{tabular}} & \multirow{2}{*}{$\begin{array}{l}p \\
0.63 \\
\end{array}$} \\
\hline & 45.78 & 5.28 & 45.39 & 4.93 & \\
\hline Anxiety after intervention & 44.44 & 5.86 & 48.44 & 3.93 & $<0.001$ \\
\hline Paired $t$-test & \multicolumn{2}{|l|}{0.008} & \multicolumn{2}{|c|}{$<0.001$} & \\
\hline
\end{tabular}

\begin{tabular}{|c|c|c|c|c|c|}
\hline \multirow{2}{*}{$\begin{array}{l}\text { Group of husbands of pregnant } \\
\text { women before intervention } \\
\text { Various aspects of anxiety }\end{array}$} & \multicolumn{2}{|c|}{ Examination group } & \multicolumn{2}{|c|}{ Control group } & \multirow[t]{2}{*}{$p$} \\
\hline & average & $\begin{array}{l}\text { standard } \\
\text { deviation }\end{array}$ & average & $\begin{array}{l}\text { standard } \\
\text { deviation }\end{array}$ & \\
\hline Opportunity (state) & 23.70 & 2.99 & 23.66 & 2.51 & 0.93 \\
\hline Personality (trait) & 22.09 & 2.98 & 22.02 & 2.92 & 0.88 \\
\hline
\end{tabular}

\begin{tabular}{|l|l|l|l|l|l|}
\hline Table 6. Mean and standard deviation for various aspects of anxiety after intervention and husband control groups \\
\hline $\begin{array}{l}\text { Group of husbands of pregnant } \\
\text { women after intervention }\end{array}$ & \multicolumn{2}{|l|}{ Examination group } & \multicolumn{2}{l|}{ Control group } & $p$ \\
\hline Various aspects of anxiety & average & $\begin{array}{l}\text { standard } \\
\text { deviation }\end{array}$ & average & $\begin{array}{l}\text { standard } \\
\text { deviation }\end{array}$ & \\
\hline Opportunity (state) & 22.93 & 2.84 & 25.46 & 2.46 & $<0.001$ \\
\hline Personality (trait) & 21.53 & 3.51 & 22.98 & 2.60 & 0.005 \\
\hline
\end{tabular}

The score of State Anxiety (A-State) was reported as 23.70 \pm 2.99 and $23.66 \pm 2.51$ in the intervention and control groups, respectively. According to the independent $t$-test, both groups were matched regarding the State Anxiety (A-State) $(p=0.93)$. A month after intervention, the score of state-anxiety was reported as $22.93 \pm 2.84$ and $25.46 \pm 2.46$ in the intervention and control groups, respectively. According to the independent $t$ test, the decrease of anxiety was significant after intervention in the test group $(p<0.001)$; however, this trend was opposite in the control group. Before intervention, the score of traitanxiety was reported as $22.09 \pm 2.98$ and $22.02 \pm 2.92$ in the intervention and control groups, respectively. According to the independent $t$-test, both groups were matched regarding the trait-anxiety score $(p=0.88)$. A month after intervention, the score of trait-anxiety was reported as $21.53 \pm 3.51$ and 22.98 \pm 2.60 in the intervention and control groups, respectively. According to the independent $t$-test, the decrease of trait-anxiety was significant after intervention in the intervention group $(p=0.005)$, while the state-anxiety increased (Tables 5,6$)$.

\section{Discussion}

According to the results of the present study, there was a significant difference in attachment scores between the intervention and control groups. Ustunsoz et al. carried out a recent cross-sectional study on parent-infant attachment (PFA) in the prenatal care units of three educational hospitals in Ankara (Turkey). The sample consisted of 144 pregnant women along with their husbands. The tools included a basic demographic information questionnaire, the maternal attachment scale of Cranly and the parent-fetal attachment scale. The attachment score was significantly higher in the husbands of women with low-risk pregnancies compared to those of high-risk pregnancy

Moreover, the attachment score was higher in mothers and spouses with planned pregnancies compared to unplanned pregnancies. Pregnant women also had a higher attachment level compared to their husbands [20]. Increased attachment was in accordance with the findings of the present study. Accord- 
ing to Jordan, involving fathers in the pregnancy experiences of their wives, along with interaction with child, can significantly increase their paternal role function. According to the results, a father's involvement in the pregnancy process can impact the health of men, women and the family as a whole [21].

In a study done by Field et al. (2008), approx. 47 women with prenatal depression were selected and randomly assigned into two groups of test and control. The data showed that a husband's participation in the process of pregnancy improves not only the mood status in couples, but also their mutual interaction [22]. Acceptance of paternal identity occurs long before the infant's birth through a husband's attachment behavior. Behaviors based on paternal-fetal attachment are rooted in a deep sense of love toward the unborn child, which is the foundation of paternal identity [23] and plays an important role in the growth and development of knowledge, attitudes and behavior in the child $[24,25]$. Parent-fetal attachment behaviors have a direct relationship with the favorable outcomes of pregnancy and health promotion in both mothers and the child. Fathers with higher attachment scores are more sensitive to the start and continuation of prenatal care, proper nutrition, adequate sleep and exercise in their wives [26]. Furthermore, they create better and more established interactions with child after birth [27]. The results of our study showed that a father's anxiety significantly decreases after attachment training in comparison to the control group. A randomized clinical trial was also done in Taiwan on 87 fathers awaiting the birth of their children (45 in the case group and 42 in the control group) who accompanied their pregnant wives in the labor and delivery room.

Two hours after the delivery, all fathers were asked to complete the anxiety questionnaire. The results showed a significant difference between the groups. The amendment of education level, the reference of delivery information and delivery expectations, along with attendance in the classes, and delivery-based education can significantly decrease the level of anxiety in fathers after birth. According to this study, the clinical implementation of prenatal educational courses based on the self-efficacy theory is an effective strategy to reduce anxiety among fathers [28]. According to the investigations, fathers often feel worried in terms of the infant's health, such as the risk of having children with disabilities, but they often feel anxiety in terms of their supportive role regarding their pregnant wives [29-31].
In addition, if the parents have ongoing support from the health-medical team during pregnancy and labor, fathers will play a more active role in participation with the pregnancy process [32]. To reduce the Hawthorne effect, the following actions were taken: the learning environment was alike in all classes for this purpose, and the Hall Hospital was used. Thus, the learning environment in terms of audio-visual, ventilation, light and noise of the educational environment was the same. Besides this, the method of education was similar in all classes and consisted of lectures, group discussions, questions and answers and the use of a slide presentation. In order to avoid overcrowding of classes, each class was also formed with the participation of 15 people. The research data was all gathered at the same point in time (before and immediately after intervention in the experimental group and in control group). In our study, there was no observer effect. The questionnaires were also completed by participants in a group discussion (between participants) while the researcher was out of the class, and at the end of the class, he returned to the class in order to answer questions.

\section{Conclusions}

Regarding the results, training on attachment skills for fathers can increase parental-fetal attachment while the father's anxiety decreases. This anxiety is effective on his interaction with his pregnant wife, pregnancy trend and the mother's anxiety. A father's anxiety is directly decreased by prenatal education, reducing the father's anxiety and providing them with sufficient awareness, which consequently indirectly impacts the mother's anxiety.

Acknowledgements. The authors would like to thank the Research Vice-chancellor of Shiraz University of Medical Sciences for financially supporting the study. The authors would also like to thank Dr. Nasrin Shokrpour at the Center for Development of Clinical Research of Nemazee Hospital for editorial assistance.

The authors would like to thank Shiraz University of Medical Sciences, Shiraz, Iran, as well as the Center for Development of Clinical Research of Nemazee Hospital and Dr. Nasrin Shokrpour for editorial assistance.

Source of funding: The present article was extracted from proposal research (proposal No. 91-5529).

Conflict of interest: The authors declare no conflict of interests.

\section{References}

1. Fowles ER. Relationships among prenatal maternal attachment, presence of postnatal depressive symptoms, and maternal role attainment. J Soc Pediatr Nurs 1996; 1(2): 75-82.

2. Nemsadze K, Silagava M. Neuroendocrine foundation of maternal-child attachment. Georgian Med News 2010; 189: 21-26.

3. Cranley MS. Development of a tool for the measurement of maternal attachment during pregnancy. Nurs Res 1981; 30(5): $281-284$.

4. Fleming AS, Ruble DN, Gordon LF, et al. Postpartum adjustment in first-time mothers: relations between mood, maternal attitudes, and mother-infant interaction. Dev Psychol 1988; 24(1): 71-81.

5. Muller ME. Prenatal and postnatal attachment: a modest correlation. J Obstet Gynecol Neonatal Nurs 1996; 25(2): 161-166.

6. Zachariah R. Attachment, social support, life stress, and psychological well-being in pregnant lowincome women: a pilot study. Clin Excell Nurse Pract 2004; 8(2): 60-67.

7. Bartlett EE. The effects of fatherhood on the health of men: a review of the literature. The Journal of Men's Health \& Gender 2004; 1(2): 159-169.

8. Berry LM. Realistic expectations of the labor coach. J Obstet Gyn Neonatal Nurs 1988; 17(5): 354-355.

9. Jordan PL. Laboring for relevance: expectant and new fatherhood. Nurs Res 1990; 39(1): 11-16.

10. Chalmers B, Meyer D. What men say about pregnancy, birth, and parenthood. J Psych Obstet Gynec 1996; 17(1): 47-52.

11. Johnson MP. An exploration of men's experience and role at childbirth. J Men's Studies 2002; 10(2): 165-182.

12. Henderson AD, Brouse AJ. The experience of new fathers during the first three weeks of life. J Adv Nurs 1991; 16(3): $293-298$.

13. Barclay L, Lupton D. The experience of new fatherhood: a socio-cultural analysis. J Adv Nurs 1999; 29(4): 1013-1020.

14. Ballard CG, Davis R, Cullen PC, et al. Prevalence of postnatal psychiatric morbidity in mothers and fathers. Br J Psychiatr 1994; 164(6): 782-788.

15. Latifses V, Bendell Estroff D, Field T, et al. Fathers massaging and relaxing their pregnant wives lowered anxiety and facilitated marital adjustment. J Bodyw Mov Ther 2005; (4)9: 277-282.

16. Weinfeld NS, Sroufe LA, Egeland B, et al. The nature of individual differences in infant-caregiver attachment. In: Cassidy J, Shaver P, eds. Handbook of attachment: theory, research, and clinical applications. New York: The Guilford Press; 1999: 68-86. 
17. Bryan AA. Enhancing parent-child interaction with a prenatal couple intervention. MCN Am J Matern Child Nurs 2000; 25(3): 139-144.

18. Adler J, Urech C, Finc N, et al. Response to induced relaxation during pregnancy: comparison of women with high versus low levels of anxiety. J Clin Psychol Med Settings 2011; 18(1): 13-21.

19. Aghamohammadi M. Religious preoperative anxiety. Ann Gen Psychiatry 2008; 69(4): 1195-1200.

20. Ustunsoz A, Guvenc G, Akyuz A, et al. Comparison of maternal-and paternal-fetal attachment in Turkish. Couples 2010; 26(2): 1-9.

21. Jordan PL. Laboring for relevance: expectant and new fatherhood. Nurs Res 1990; 39(1): 11-16.

22. Field $\mathrm{T}$, Figueiredo B, Hernandez-Reif $\mathrm{M}$, et al. Massage therapy reduces pain in pregnant women, alleviates prenatal depression in both parents and improves their relationships. J Bodyw Mov Ther 2008; 12(2): 146-150.

23. Condon JT, Cortlindale C. The correlates of anttenatal attachment in pregnant women. Br J Med Psychol 1997; 70(4): 359-372.

24. Akbarzade $M$, Rafiee $B$, Asadi N, et al. The effect of maternal relaxation training on reactivity of non-stress test, Basal fetal heart rate, and number of fetal heart accelerations: a randomized controlled trial. Int J Community Based Nurs Midwifery 2015; 3(1): 51-59.

25. Akbarzade M, Rafiee B, Asadi N, et al. Comparative effect of attachment and relaxation training on perception of fetal movement and mother's anxiety in primiparous women: a randomized controlled study. Trends in Medical Research 2016; 11(2): 62-68.

26. Lindgren K. Relationships among maternal-fetal attachment, prenatal depression, and health practices in pregnancy. Res Nurs Health 2001; 24(3): 203-217.

27. Weaver RH, Cranley MS. An exploration of paternal-fetal attachment behavior. Nurs Res 1983; 32(2): 68-72.

28. Li HT, Lin KC, Chang SC, et al. A birth education program for expectant fathers in Taiwan: effects on their anxiety. Birth 2009; 36(4): 289-296.

29. Sjögren B. Reasons for anxiety about childbirth in 100 pregnant women. J Psychosom Obstet Gynaecol 1997; 18(4): $266-272$.

30. Vehviläinen-Julkunen K, Liukkonen A. Fathers' experiences of childbirth. Midwifery 1998; 14(1): 10-17.

31. Eriksson C, Westman G, Hamberg K. Content of childbirth-related fear in Swedish women and men - analysis of an open-ended question. J Midwifery Womens Health 2006; 51(2): 112-118.

32. Gungor I, Beji NK. Effects of fathers' attendance to labor and delivery on the experience of childbirth in Turkey. West J Nurs Res 2007; 29(2): 213-231.

Tables: 6

Figures: 1

References: 32

Received: 17.02.2017

Revised: 16.03 .2017

Accepted: 10.04.2017

Address for correspondence:

Marzieh Akbarzadeh, MSc

Maternal-Fetal Medicine Research Center

Department of Midwifery

School of Nursing and Midwifery

Shiraz University of Medical Sciences

Shiraz

Iran

Tel.: 0711-6474250

E-mail: akbarzadm@sums.ac.ir 